\title{
The Opioid Crisis: A Problem That Defies Solution?
}

\author{
Olubunmi Olanrewaju \\ Southern University and A \& M College, Department of Public Policy \& Urban Affairs, Baton Rouge, \\ Louisiana
}

\begin{abstract}
Mortality resulting from drug abuse (or overdose) has tremendously increased over the past decades. Drug abuse (or overdose) has become a critical public health concerns or issue in the United States of America due to its related alarming rate of death. Death rates from opioid overdose have surged in the past years and the opioid crisis is worsening at an alarming rate. There seems to be no quick fix to the opioid problem therefore it is essential to approach the problem in a comprehensive manner that includes overdose prevention. Accordingly, early intervention in childhood experiences can mean the difference between a healthy adult life and substance use. This article reviews current literature to investigate the relationship between Adverse Childhood Experiences (ACEs) and drug overdose. ACEs have a dose-dependent effect on health outcomes hence, direct impacts on childhood intervention can pay large dividends to the society and health in the future. Therefore, the study recommends that developing new partnerships and working across sectors including public health, government, healthcare services, social services, education, housing, non-governmental organizations, media can help prevent early adversity and in turn, addiction in later life.
\end{abstract}

Keywords: Opioid crisis, Drug abuse, Drug overdose, Adverse childhood experiences

DOI: $10.7176 / \mathrm{PPAR} / 9-8-08$

Publication date: August $31^{\text {st }} 2019$

\subsection{Introduction}

Not only has the average availability of both legal and illegal opioids risen in the past 15 years but opioid-related deaths have also climbed in many countries (OECD, 2019). Prescription and illicit opioids are the "main driver of drug overdose deaths" (CDC, 2018). On average, 130 people in the United States die every day from an opioid overdose (CDC, 2017). The National Institute on Drug Abuse (NIDA) at the National Institutes of Health (NIH) has described opioid misuse and addiction as "a serious national crisis that affects public health as well as social and economic welfare" (NIH, 2019). Many literatures have emphasized on a myriad of interventions to reverse the opioid crisis, but more distal primary prevention strategies that have evidence base are underutilized till date (Comptom et. al, 2019). This study therefore calls the attention of the government and the society at large to the unintended consequences of Adverse Childhood Experiences (ACEs) on future health outcomes. Why do people develop addiction to misuse, abuse and overdose on opioids? Is this opioid use disorder an opioid crisis or a trauma crisis? The study hypothesizes a reason for opioid complications, such as opioid use disorder. One answer is likely trauma. Information from the ACE study suggests that traumatic stressors during childhood and adolescence represent a common pathway to a variety of important long-term behavioral, health, and social problems (Anda et al., 2006). This report contributes to existing literature on curbing the overuse of opioids by calling for resources and attention to mitigate ACEs. The aim is to draw the attention of policymakers and the society at large to the unintended consequence of adverse childhood experience and its negative future impact.

\subsection{Literature Review}

2.1 The Opioid Epidemic

According to the Centers for Disease Control and Prevention (CDC), both the number of opioid overdoses and the amount of prescription opioids in America have quadrupled since 1999 (CDC, 2018). The massive increase in prescribing has occurred even though there has not been an overall change in the amount of pain Americans have reported in the period. From 1999-2017, almost 400,000 people died from an overdose involving any opioid, including prescription and illicit opioids (Scholl et al., 2018). Americans across all socioeconomic groups have been adversely impacted by misuse of prescription and illicit opioids (Joynt et al., 2013). Florence et al. (2016) estimate that prescription opioid misuse increases healthcare and substance abuse treatment costs, increases criminal justice costs, and reduces productivity among those who do not die of overdose. Opioid addiction costs many lives, harms livelihoods, depresses labor market participation, and entails significant public healthcare spending (OECD, 2018). 


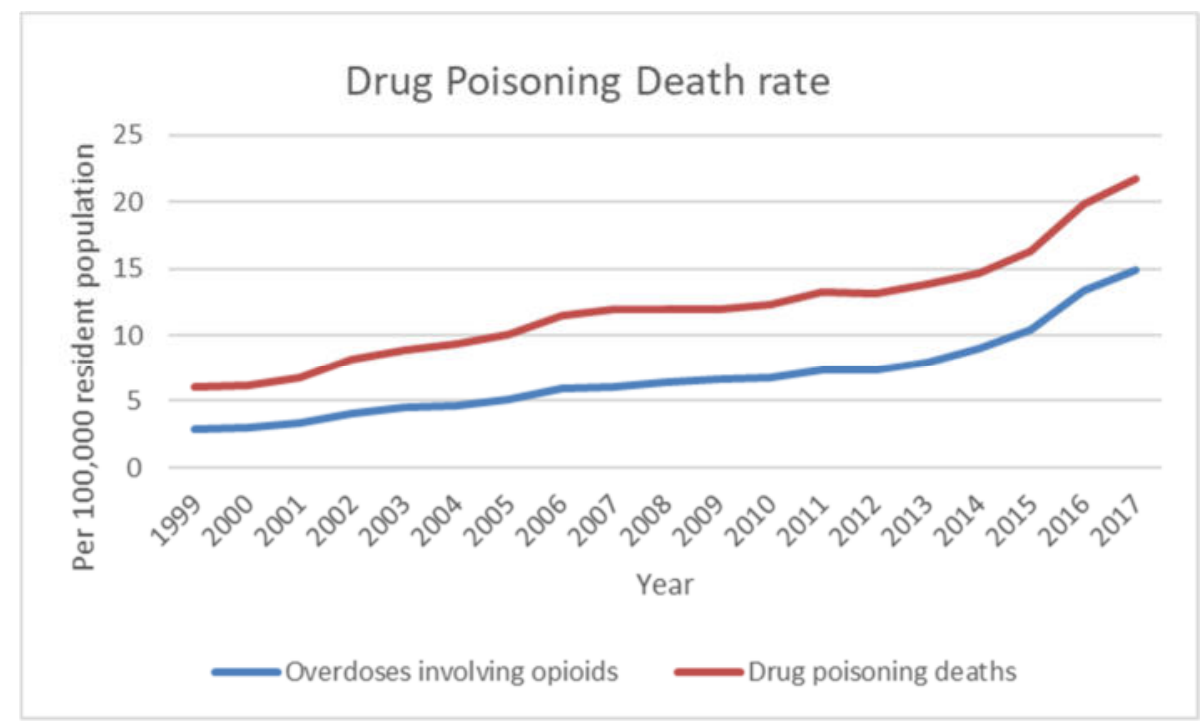

Figure 2.1: Drug Overdose Deaths in the United States, 1999-2017

Source: National Center for Health Statistics, National Vital Statistics System. Mortality

Figure 2.1 shows that overdose deaths have surged in the last two decades, particularly as (illicit) synthetic opioids have become more available. The rate of opioid overdose increased from 2.9 per 100,000 standard population in 1999 to 14.9 in 2017 while drug overdose deaths increased from 6.1 to 21.7 in the same period.

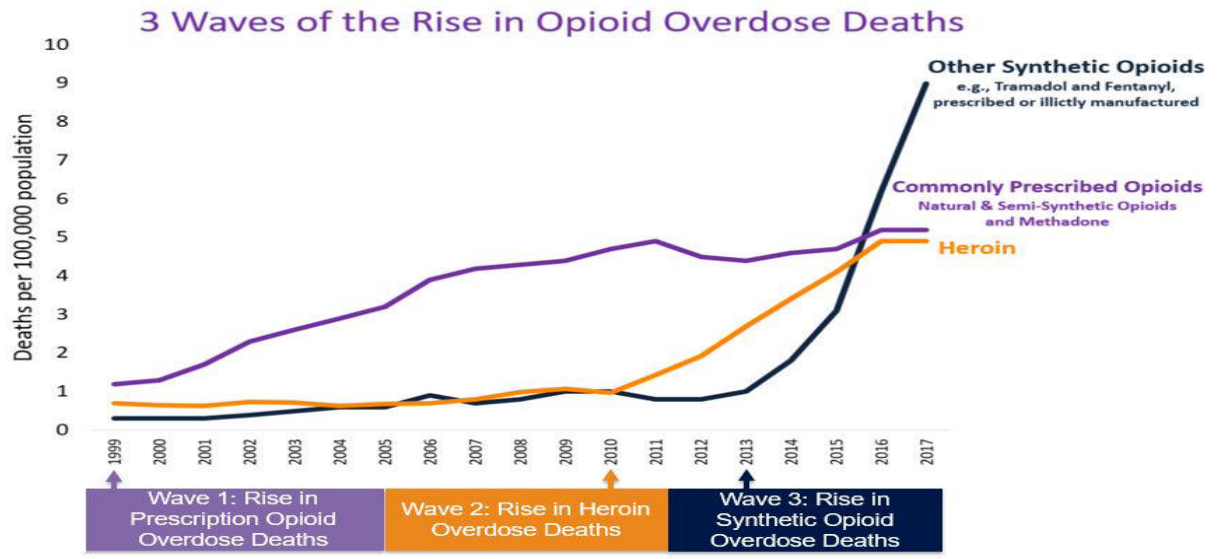

Figure 2.2: Waves of the Rise in Opioid Overdose Deaths from 1999-2017

Figure 2.2 reveals the 3 waves of the opioid epidemic. The first began with increased prescription of opioids in the 1990s (Rudd et al., 2016). This increase in opioid prescription resulted in increased overdose deaths since at least 1999. The second wave which started in 2010 involved a rise in overdose death involving heroin while the third wave from 2013 came with an upsurge in overdose deaths involving synthetic opioids (CDC, 2018).

\subsection{Is There a Quick Fix to the Opioid Crisis?}

Deaths from drug overdose are an increasing public health burden in the United States (Rudd, 2016). The U.S. opioid epidemic is continuing, and the ongoing epidemic of opioid deaths requires intense attention and action (Hedegaard et al., 2018). Existing interventions are getting old and there are continued efforts across public and private sectors to seek emergency measures, tamp down access to prescription opioids, control illicit supplies, provide rapid treatments, and develop palliative substitutes (Hodge, 2019). Can we then say there is no quick fix to the opioid problem? In the study conducted by the CDC and Kaiser Permanente, some health-related outcomes, including addiction worsened with repeated exposure to adverse childhood experiences (Felitti et al., 1998). There 
is empirical as well as theoretical rationale for preventing substance misuse and related outcomes through primary prevention aimed at addressing risk and protective factors in childhood and adolescence (Comptom et al., 2019).

\subsection{Adverse Childhood Experiences (ACEs)}

Adverse childhood experiences are common. These experiences include emotional, physical and sexual abuse; emotional and physical neglect; growing up in a dysfunctional household with substance abuse, criminality of household members, mental illness among household members, parental discord and illicit drug use (Dube et al., 2003). In the adverse childhood experiences study conducted by Dube et al. (2003), a retrospective cohort study of more than 8600 adults visiting a California primary care clinic shows that the greater the number of early childhood abuse and neglect experiences that respondents reported, the more likely they were to have used drugs as adolescents or as adults, to have a substance use disorder (SUD), and to have initiated drug use at an early age. Hence, a strong relationship between the number of childhood exposures and the number of health risk factors for leading causes of death in adults. Anda et al. (2006) suggested that prevention and remediation of our nation's leading health and social problems is likely to benefit from understanding that many of these problems tend to be co-morbid and may have common origins in the enduring neurodevelopmental consequences of abuse and related adverse experiences during childhood.

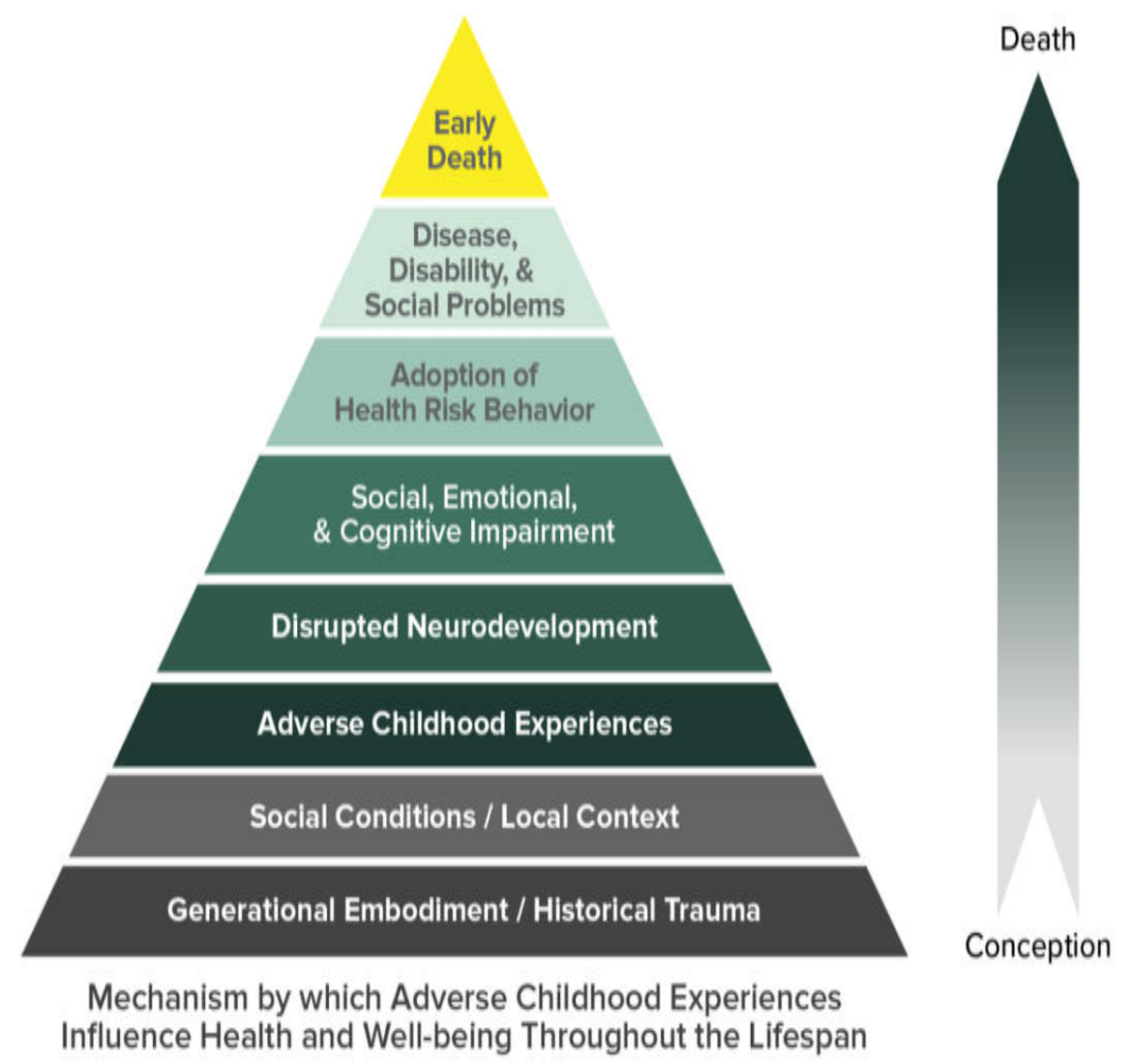

Figure 2.3: CDC-Kaiser ACE Study Pyramid

Source: Centers for Disease Control and Prevention, 2019

\subsection{Research Sources}

This study is purely descriptive in nature but follows narrative research design. The study uses a Boolean literature search to look for relevant literature for the purposes of discussion. The study utilized journals, and secondary sources of information from google scholar, OmniMedicalSearch.com, MedNets, Welch Medical Library, and ClinicalTrials.gov. Based on the search, the report utilizes only literature that used a data from the Organization for Economic Co-operation and Development (OECD), National Center for Health Statistics and Centers for 
Diseases Control and Prevention (CDC) for the purpose of validity and reliability. Relevant journals were also accessed to understand and profile solution to the opioid crisis.

\subsection{Probable Solution from a Multigenerational View}

Primary prevention to reduce child abuse and neglect and other forms of adverse childhood experiences may reduce a person's risk for developing substance use disorder later in life (Fortson et al., 2016). If we want to break the cycle of addiction for future generations, we must also think about health in a multigenerational view (Tilson, 2018). Dr. Daniel Sumrok, director of the Center for Addiction Sciences at the University of Tennessee Health Science Center's College of Medicine studied post-traumatic stress disorder and said addiction shouldn't be called "addiction" but should be called "ritualized compulsive comfort-seeking" (Lingenza et al., 2018:28;Stevens, 2017). He concluded that tens of thousands of people lead desperate lives, most of them unknowingly fueled by their childhood experiences, hence, substance use is not a disorder but a normal learned response to trauma. Chemical dependency takes many forms, and many of them are often linked to trauma sustained in developmental years (Silvermist, 2019). The time delay between exposure during childhood and recognition of health problems in adulthood is lengthy, hence the relationship between childhood experiences and adult health status is likely to be overlooked (Felitti et al., 2019). Adverse childhood experiences affect development and behavior and, if left unaddressed, threaten long-term health well-being (NCSL, 2018). Data from the National Conference on Legislatures, as well as many other organizations, points to a close relationship between childhood adversity and the development of opioid dependency. One key element of treating and fundamental to helping individuals with opioid addiction in recovery and to stay clean is identifying their history of trauma, recognizing triggers of substance abuse, and providing trauma-informed care (Silvermist, 2019). Comptom et al. (2019) believes that reducing the risks of initiating opioid misuse by addressing modifiable childhood and adolescent risk may be another "ounce of prevention" that makes a substantial difference in a society and health care system reeling from one of the worst drug crises ever seen in the U.S.

\section{Conclusion and Recommendation}

There seems to be no quick fix by any means. Felitti et al. (2019) reiterated that increased awareness of the frequency and long-term consequences of adverse childhood experiences may lead to improvements in health promotion and disease prevention programs. Early intervention in childhood trauma can mean the difference between a healthy adult life and significant psychological impairment due to substance use. This will pay large dividends to the society and health in the future. It takes the media, the political and the societal will with a long view to care. Developing new partnerships and working across sectors including public health, government, healthcare services, social services, education, housing, non-governmental organizations, media can help prevent early adversity and in turn, addiction in later life. Primary prevention of adverse childhood experiences will ultimately require societal changes that improve the quality of family and household environments. Children who are nurtured and supported in childhood are more likely to succeed and grow into happy, healthy, and productive adults.

\section{References}

Anda, R.F., Felitti, V.J., Walker J., Whitfield, C.L., Bremner, J.D., Perry, B.D., Dube, S.R. \& Giles, W.H. (2006). The Enduring Effects of Abuse and Related Adverse Experiences in Childhood: A Convergence of Evidence from Neurobiology and Epidemiology. European Archives of Psychiatry and Clinical Neurosciences, 2006; 256(3):174-86.

Centers for Disease Control and Prevention (2019). About the CDC-Kaiser ACE Study. National Center for Injury Prevention and Control, Division of Unintentional Injury Prevention. December 2018

Centers for Disease Control and Prevention (2018). NCHS National Vital Statistics System, Mortality. CDC WONDER, Atlanta, GA: US Department of Health and Human Services, CDC; 2018. https://wonder.cdc.gov

Centers for Disease Control and Prevention (2018). Prescription Opioid Data. National Center for Injury Prevention and Control, Division of Unintentional Injury Prevention. December 2018

Centers for Disease Control and Prevention (2017). Opioid Overdose: Understanding the Epidemic. Wide-ranging online data for epidemiologic research (WONDER). Atlanta, GA: CDC, National Center for Health Statistics; 2017. Available at http://wonder.cdc.gov.

Compton, W. M., Jones C.M., Baldwin G.T., Harding F.M., Blanco C. \& Wargo E.M. (2019). Targeting Youth to Prevent Later Substance Use Disorder: An Underutilized response to the US Opioid Crisis. AJPH Perspectives Supplement 3, 2019, Vol 109, No. S3

Dube, S.R., Felitti V. J., Dong M., Chapman D.P., Giles W.H. \& Anda R. F. (2003). Childhood abuse, neglect, and household dysfunction and the risk of illicit drug use: The Adverse Childhood Experiences study. Pediatrics. 2003;111(3):564-572. 
Felitti, V.J., Anda R.F., Nordenberg D., Williamson D. F., Spitz A. M., Edwards V., Koss M.P. \& Marks J. S. (1998). Relationship of Childhood Abuse and Household Dysfunction to Many of the Leading Causes of Death in Adults. The Adverse Childhood Experiences (ACE) Study. 1998 American Journal of Preventive Medicine. PII S0749-3797(98)00017-8

Felitti, V.J, Anda R. F., Nordenberg D., Williamson D. F., Spitz A. M., Edwards V., Koss M. P. \& Marks J. S. (2019). Relationship of Childhood Abuse and Household Dysfunction to Many of the Leading Causes of Death in Adults: The Adverse Childhood Experiences (ACE) Study. American Journal of Preventive Medicine, 56(6):6774-786

Florence, C., Zhou, C., Luo, F. \& Xu, L. (2016). “The Economic Burden of Prescription Opioid Overdose, Abuse, and Dependence in the United States, 2013.” Medical Care, 54(10): 901-906.

Fortson, B., Klevens J., Merrick M.T., Gilbert L.K. \& Alexander S.P. (2016). Preventing child abuse and neglect: a technical package for policy, norm, and programmatic activities. Atlanta, GA: National Center for Injury Prevention and Control, Center for Disease Control and Prevention; 2016

Hedegaard, H., Miniño A.M., \& Warner M. (2018). Drug overdose deaths in the United States, 1999-2017. NCHS Data Brief, no 329. Hyattsville, MD: National Center for Health Statistics; 2018.

Hodge, J.G. (2019). Innovative Law and Policy Responses to the Opioid Crisis. The Journal of Law, Medicine \& Ethics, 47 (2019): 173-176

Joynt M., Train M.K., Robbins B. W., Halterman J. S., Caiola E. \& Fortuna R. J. (2013). The impact of neighborhood socioeconomic status and race on the prescribing of opioids in emergency departments throughout the United States. J Gen Intern Med. 2013 Dec;28(12):1604-10

Ligenza, L., Johnson K. \& Gerrity P. (2018). Impact of ACEs and Adoption of Trauma-Informed Approaches in Healthcare Settings Center. SAMHSA-HRSA Center for Integrated Health Solutions. Retrieved from https://integration.samhsa.gov/about-us/ACES_in_TIC.pdf

NCSL (2018). Opioids and Early Adversity: Connecting Childhood Trauma and Addiction. National Conference of State Legislatures. Archived Webinar. April 6, 2018.

NIH (2019). Opioid Overdose Crisis, National Institute on Drug Abuse. Available at https://www.drugabuse.gov/drugs-abuse/opioids/opioid-overdose-crisis

OECD (2019). Addressing Problematic Opioid Use in OECD Countries, OECD Health Policy Studies, OECD Publishing, Paris. https://doi.org/10.1787/a18286f0-en.

OECD (2019). Description of the opioid crisis in Australia, Canada and the United States. OECD library

OECD (2018) OECD Economic Surveys: United States. June 2018 Overview. Available at http://www.oecd.org/eco/surveys/Overview-United-States-2018-OECD.pdf

Rudd, R.A., Seth P., David F. \& Scholl L. (2016). Increases in Drug and Opioid-Involved Overdose Deaths United States, 2010-2015. MMWR Morbidity Mortal Weekly Rep 2016; 65:1445-1452. DOI: http://dx.doi.org/10.15585/mmwr.mm655051e1

Scholl, L., Seth P., Kariisa M., Wilson N. \& Baldwin G. (2018). Drug and Opioid-Involved Overdose Deaths United States, 2013-2017. MMWR Morb Mortal Wkly Rep 2019; 67:1419-1427. DOI: http://dx.doi.org/10.15585/mmwr.mm675152elexternal icon.

Silvermist (2019). Trauma. Pyramid Healthcare Inc. 2019 Silvermist, LLC. Available at https://silvermistrecovery.com/trauma-informed-care/

Stevens, J. E. (2017). ACE Study, Adverse childhood experiences, Child trauma, Community prevention programs, Solutions. ACES Too High News. Assessed on https://acestoohigh.com/2017/05/02/addictiondoc-says-stop-chasing-the-drug-focus-on-aces-people-can-recover/ May 27, 2019.

Tilson, E. C (2018). Adverse Childhood Experiences (ACEs): An Important Element of a Comprehensive Approach to the Opioid Crisis. North Carolina Medical Journal. 79(3) :166-169 